\title{
'Thunder Measure Vet Device': een praktische en objectieve methode om de lichaamsconditie van melkvee te schatten
}

\author{
The 'Thunder Measure Vet Device': an innovative tool to objectively score \\ the body condition of dairy cows in the field
}

\author{
${ }^{1}$ T. Dewaele, ${ }^{1}$ M. Van Eetvelde, ${ }^{2}$ G. Vertenten, ${ }^{1}$ G. Opsomer \\ ${ }^{1}$ Vakgroep Voortplanting, Verloskunde en Bedrijfsdiergeneeskunde, Faculteit Diergeneeskunde, \\ Universiteit Gent, Salisburylaan 133, B-9820 Merelbeke \\ ${ }^{2}$ Elanco Animal Health, Antwerpen, Belgium
}

geert.opsomer@ugent.be

\section{AMENVATTING}

Het op regelmatige tijdstippen bepalen van de lichaamsconditie van koeien is in de moderne melkveehouderij een belangrijk instrument om het nutritionele management van de dieren te optimaliseren. De 'Thunder Measure (TM) Vet Device' werd door Ingenera SA, Zwitserland ontwikkeld om op een objectieve en eenvoudige manier de conditie of "body condition score" (BCS) bij melkkoeien te bepalen. Aan de hand van een smartphone-applicatie gekoppeld aan een lasertoestel wordt een analyse gemaakt van drie foto's van de dorsale zijde van het dier, bijvoorbeeld in de voedergang. In dit onderzoek werden de correlatie en de herhaalbaarheid van de TMVet Device berekend in vergelijking tot de conventionele BCS-bepaling en de ultrasonografisch bepaalde "backfat thickness" (BFT). De conventionele BCS werd gemeten door een dierenarts ervaren in het bepalen van de conditie van melkkoeien en drie minder ervaren studenten diergeneeskunde. Bij dezelfde koeien werd de lichaamsconditie ook bepaald aan de hand van de BFT. De resultaten bekomen via het gebruik van de TM-Vet Device waren slechts matig gecorreleerd met de BFT ( $r=0,38 ; P<0,001)$, maar vertoonden een hoge correlatie met de BCS bepaald door de ervaren dierenarts $(r=0,82 ; P<0,001)$. Bovendien was er een goede overeenkomst tussen de resultaten bekomen met behulp van TM-Vet Device en deze bekomen door de ervaren dierenarts. Er werd een grote variatie gezien in de BCS bepaald door de studenten, waardoor ook de correlatie met de TM-Vet Device sterk varieerde van $r=0,23(P<0,05)$ tot $r=0,74(P<0,001)$. De herhaalbaarheid van de TM-Vet Device-methode was met $91 \%$ zeer hoog. Enkel door de dierenarts ervaren in het scoren van de BCS (93\%) en met de bepaling van de BFT $(96 \%)$ werd een hogere herhaalbaarheid bereikt. Bij magerdere dieren werd een overschatting gezien van de BCS gemeten met behulp van de TM-Vet Device in vergelijking met de BCS waargenomen door de ervaren dierenarts, maar deze nam af naarmate de door de dierenarts toegekende conditie toenam.

Het eenvoudig gebruik en de betrouwbaarheid van de resultaten laten toe te stellen dat de TM-Vet Device een plaats kan krijgen in het management van een hoogproductief melkveebedrijf.

\section{ABSTRACT}

The scoring of the body condition at specific time points during the lactation cycle has proven to be essential in the nutritional management of modern dairy herds. The 'Thunder Measure (TM) Vet Device' has recently been developed by Ingenera SA, Switzerland to accurately and objectively measure the body condition score (BCS) of dairy cows in the field. Based on a smartphone app linked to a laser device, the system makes an analysis of three dorsal view photographs taken, for example, when cows are lined up in the feed alley. In the present study, the correlation and repeatability of the system were examined in comparison with the conventional visual measurement of BCS and ultrasonographic measurement of the backfat thickness (BFT). The conventional measurement of the BCS was done by a veterinary surgeon experienced in body condition scoring and by less experienced veterinary undergraduate students. The results obtained via the TM Vet Device were only moderately correlated with 
the BFT measurements $(\mathrm{r}=0.38, \mathrm{P}<0.001)$, but were highly correlated $(\mathrm{r}=0.82, \mathrm{P}<0.001)$ and showed good agreement with the BCS results obtained by the experienced veterinary surgeon. The BCS results obtained by the undergraduate students were highly variable, leading to a highly variable correlation with the results gathered using the TM Vet Device $(\mathrm{r}=0.23(\mathrm{P}<0.05)$ to $\mathrm{r}=0.74(\mathrm{P}<0.001))$. The repeatability of the results obtained by the device was very high (91\%). Only the repeatability of the results obtained by the experienced veterinarian (93\%) and the BFT measurement $(96 \%)$ were higher. In lean animals, some overscoring by the device was noted in comparison with the scores given by the experienced veterinary surgeon, although this overscoring diminished as the body condition score assigned by the veterinary surgeon increased.

The ease to use and the accuracy of the results obtained allow the TM Vet Device to be considered a useful tool in the nutritional management of a modern dairy herd.

\section{INLEIDING}

De huidige melkkoeien produceren grote hoeveelheden melk en dit vooral tijdens de lactatiepiek na het afkalven. Door de wanbalans tussen een onvoldoende opname van en de verhoogde behoefte aan voedingstoffen komen vrijwel alle moderne koeien na het afkalven in een negatieve energiebalans terecht (Bossaert, 2010). Door de mobilisatie van lichaamsvet tijdens de vroege lactatie tracht de koe een antwoord te bieden aan deze negatieve energiebalans. Energetisch gezien zorgt het gebruik van lichaamsweefsel voor ongeveer 30\% van de hoeveelheid melk geproduceerd gedurende de eerste maand van de lactatie (Bines en Hart, 1982). Tamminga et al. (1997) toonden aan dat hoogproductieve melkkoeien gedurende de eerste acht weken na het afkalven tot $30,9 \mathrm{~kg}$ vet en $4,6 \mathrm{~kg}$ eiwit mobiliseren om daarmee $550 \mathrm{~kg}$ melk te produceren.

Op het moment van het afkalven is er dus een zekere hoeveelheid energiereserve nodig wil de koe de uitdaging van de negatieve energiebalans na het afkalven het hoofd kunnen bieden en die hoeveelheid melk produceren waartoe zij genetisch in staat is. Wanneer er echter een te grote hoeveelheid vet is opgeslagen en de koe afkalft in een te hoge conditie, is er een verhoogde kans op problemen met leververvetting en ketonemie terwijl er eveneens een hogere kans op lebmaagverplaatsingen, laminitis, mastitis en metritis zal zijn (Morrow, 1976; De Koster en Opsomer, 2012). Een belangrijk punt in het nutritionele management van melkkoeien bestaat er dan ook uit om bij de berekening van het rantsoen niet alleen rekening te houden met de hoeveelheid melk die wordt geproduceerd, maar evenzeer met de conditie van de koeien. Vooral in de tweede helft van de lactatie is het belangrijk om het rantsoen en dan vooral de krachtvoedergift af te stemmen op zowel de geproduceerde hoeveelheid melk als de conditie van de koeien. Hiervoor dienen zowel de nutritionist die het rantsoen berekent en samenstelt als de veehouder die het rantsoen aan de koeien verstrekt, op regelmatige tijdstippen de hoeveelheid opgeslagen energie onder de vorm van vet, te schatten. Dit laatste doet men door op regelmatige tijdstippen de lichaamsconditie van de koeien te bepalen (Bewley et al., 2008; Roche et al., 2009 en 2013).

Sedert lange tijd wordt geprobeerd om de energiereserves die in de vorm van subcutane en intra-abdominale vetdepots bij de koeien worden opgeslagen, in te schatten (Edmonson et al., 1989; Bewley et al., 2008; Roche et al., 2009). Alhoewel tegenwoordig wordt ingezien dat, naar analogie met de humane geneeskunde, het schatten van de hoeveelheid vet opgeslagen in het abdomen nog belangrijker is met betrekking tot de gevoeligheid voor latere gezondheidsproblemen dan het schatten van de hoeveelheid subcutaan vet (De Koster en Opsomer, 2012 en 2013), zijn de meeste voorhanden zijnde methoden beperkt tot het inschatten van de hoeveelheid opgeslagen subcutaan vet. De hiervoor meest gebruikte methode is het bepalen van de BCS. Er zijn verschillende manieren om de BCS te schatten. De meest eenvoudige methoden zijn gebaseerd op visuele waarnemingen eventueel aangevuld met tactiele ter hoogte van specifieke plaatsen op het lichaam van de melkkoe die bekend staan wegens subcutane vetopstapeling (Edmonson et al., 1989; Roche et al., 2009 en 2013). De schaal die hiervoor gehanteerd wordt, is internationaal niet eenduidig. Zo zijn de meest gebruikte systemen voor het bepalen van de BCS in de Verenigde Staten en Ierland gebaseerd op een vijfpuntenschaal, terwijl dit in Australië en Nieuw-Zeeland respectievelijk een acht- en tienpuntenschaal is. Bovendien maken de systemen in de Verenigde Staten en Australië enkel gebruik van visuele waarneming, terwijl in Ierland en Nieuw-Zeeland ook gepalpeerd wordt om de hoeveelheid subcutaan opgeslagen vet te schatten. In een vergelijkende studie van Roche et al. (2004) werd echter geconcludeerd dat er een sterke correlatie bestaat tussen de verschillende methoden die internationaal gebruikt worden.

De subjectiviteit van deze methoden stelt echter een probleem. Meer bepaald blijkt dat scores uitgevoerd op basis van het visueel scoren te sterk variëren wanneer ze door verschillende personen bij één en dezelfde koe worden toegepast (Kristensen et al., 2006), terwijl ook de herhaalbaarheid van dergelijke scores vaak onvoldoende is (Pryce et al., 2014). Een eerste poging om tot een objectievere inschatting van de hoeveelheid opgeslagen subcutaan vet te komen, was het echografisch bepalen van de "backfat thickness" (BFT) (Schröder en Staufenbiel, 2006). Hierbij wordt een lineaire sonde van 5,0-7,5 MHz gebruikt. De positie van de sonde wordt bepaald door een denkbeeldige lijn te trekken tussen de tuber coxae en tuber ischiadicum. De sonde wordt vervolgens geplaatst op de overgang van de voorste twee derden naar het 
achterste derde (ongeveer ter hoogte van de aanhechtingsplaats van de eerste staartwervel) (Figuur 1). Het rugvet wordt aldus afgelijnd door de huid en de fascia trunci profunda, die zich bovenop de musculus gluteus medius bevindt. De huid heeft een dikte van 5-6 mm, wat bijgevolg van de meting (vet en huid) afgetrokken moet worden. Een koe met een BFT van $6 \mathrm{~mm}$ bezit praktisch geen vet (Schröder en Staufenbiel, 2006). Klawuhn en Staufenbiel (1997) toonden aan dat een toenemende evolutie in BFT van $1 \mathrm{~mm}$ overeenkomt met $5 \mathrm{~kg}$ lichaamsvet. Tevens is bekend dat een verandering van BCS met 1 punt correspondeert met $50 \mathrm{~kg}$ lichaamsvet. Er werden verscheidene studies uitgevoerd om de correlatie tussen de hoeveelheid in het slachthuis gemeten karkasvet (in $\mathrm{mm}$ ) en de BFT (in mm) te bepalen. In een studie van Staufenbiel en Schröder (2006) varieerden de correlaties tussen deze twee parameters tussen 0,72 en 0,92. De gemiddelde afwijking tussen de echografisch gemeten BFT en de gemeten hoeveelheid karkasvet varieerde tussen 1,6 tot 1,9 $\mathrm{mm}$. De discrepantie werd groter wanneer het rugvet dikker werd. Er werd bovendien aangetoond dat magerder vee met behulp van echografie vaak overschat en vetter vee onderschat werd. De herhaalbaarheid van de echografische BFT-bepaling werd in deze review ook geanalyseerd. De correlatie tussen de opeenvolgende metingen was 0,975 met een gemiddeld verschil van 0,72 $\mathrm{mm}$ (Brethour, 1992). In een studie van Van Eetvelde et al. (2011) werd een hoge correlatie $(r=0,71 ; p<0,001)$ gevonden tussen de BFT en de BCS voor wat betreft het bepalen van de hoeveelheid subcutaan vet. Domecq (1995) vergeleek de BCS met de echografische metingen van de hoeveelheid subcutaan vet opgeslagen ter hoogte van de lumbale regio, het bekken en de staartbasis. De BCS was evenwaardig aan het echografisch meten om de hoeveelheid subcutaan vet bij melkkoeien te bepalen (Domecq, 1995).

Momenteel wordt volop verder gezocht naar alternatieve, bij voorkeur geautomatiseerde systemen om conditiescores routinematig te bepalen, bijvoorbeeld door het ontwikkelen van specifieke beeldanalysesystemen (Bewley et al., 2008; Halachmi et al., 2008; Bercovich et al., 2013; Halachmi et al., 2013). De keuze tussen de verschillende methoden blijft steeds een afweging tussen snelheid en toepasbaarheid onder praktijkomstandigheden, prijs en accuraatheid. Om een evenwicht in deze eisen te vinden, ontwikkelde het Zwitserse bedrijf Ingenera SA de 'Thunder Measure Vet Device' (TM-Vet Device). Dit toestel gekoppeld aan een applicatie past in het moderne, digitale tijdperk, waarin het gebruik van hard- en software voor het managen van steeds groter wordende melkveebedrijven een belangrijke rol speelt.

Het doel van de hier beschreven studie was om de overeenkomst tussen de TM-Vet Device en de visuele BCS-bepaling door een ervaren dierenarts te onderzoeken. Het was met name de bedoeling om na te gaan of de TM-Vet Device een waardig, herhaalbaar en bovendien objectief alternatief is voor de visuele BCS-bepaling. Ook werd de overeenkomst tussen de TM-Vet Device en de bepaling van de BFT onderzocht. Daarnaast werd de herhaalbaarheid van de TM-Vet Device bepaald ten opzichte van deze van de andere methoden.

\section{MATERIAAL EN METHODEN}

\section{Bedrijf en dieren}

De data gebruikt in het hier beschreven onderzoek werden in november 2014 verzameld op het melkveebedrijf van de schoolhoeve Axelwalle in Oudenaarde. Dit bedrijf werd geselecteerd omwille van het hoge niveau van het management, de bereidwilligheid van de veehouder om aan het onderzoek mee te werken en het voorhanden zijn van een draadloze internetverbinding. Het bedrijf telde een vijftigtal hoogproductieve holstein-friesiankoeien. De koeien werden er tweemaal daags gemolken, om 6 uur en om 17 uur. Alle lacterende koeien kregen eenzelfde rantsoen. $\mathrm{Er}$ werden zestig dieren in het onderzoek opgenomen: 43 lacterende koeien, 7 droogstaande koeien en 10 hoogdrachtige vaarzen. De lacterende koeien bevonden zich in de melkveestal en werden er vastgezet in het voederhek. De droogstaande koeien en de vaarzen bevonden zich in een andere stal in ingestrooide boxen, en ook zij werden vastgezet in het voederhek. Volgens de melkcontrolegegevens van november 2014 bedroeg de gemiddelde 305-dagen productie 11.130 liter met 3,8 \% vet en 3,5\% eiwit, bij gemiddeld 154 dagen in lactatie. De lacterende en droge koeien hadden een gemiddelde leeftijd van drie jaar en tien maanden. Van de koeien waren er 21 dieren in eerste, 11 dieren in tweede en 18 dieren in derde lactatie of hoger. Het geselecteerde jongvee had een leeftijd tussen 20 en 23 maanden.

\section{Onderzoeksprotocol}

Alvorens het eigenlijke onderzoek werd opgestart, werd aan drie laatstejaarsstudenten diergeneeskunde (Faculteit Diergeneeskunde, Universiteit Gent) aangeleerd om de BCS via de visuele methode volgens Edmonson (Edmonson et al., 1989) te bepalen. Aan een vierde student werd door een ingenieur van Ingenera SA uitgelegd en gedemonstreerd hoe de TM-Vet Device te gebruiken. Er waren twee onderzoeksdagen voorzien, waarop zowel de lacterende koeien als de vaarzen en droogstaande koeien na de ochtendmelkbeurt vastgezet werden aan het voederhek. Vooraf werden lijsten opgemaakt met alle te scoren dieren, zodat fouten aangaande identificatie vermeden werden. Alle dieren werden individueel gescoord door de verschillende deelnemers en dit volledig onafhankelijk van elkaar. Na afloop van het scoren werden de resultaten onmiddellijk verzameld door de coör- 
dinator van het onderzoek, om ervoor te zorgen dat de twee scoremomenten volledig onafhankelijk van elkaar verliepen.

\section{BCS volgens Edmonson}

De techniek van visuele scoring werd toegepast door een dierenarts ervaren in het scoren van de BCS en drie studenten die er recentelijk in getraind waren, maar in het verleden nog niet intensief gescoord hadden. Elke persoon startte met het scoren op een verschillende plaats in de stal, waardoor er geen onderlinge communicatie mogelijk was. Na identificatie van het individuele dier werden de acht anatomische plaatsen apart gescoord volgens Edmonson et al. (1989) van 1 tot 5 met een interval van 0,25. Achteraf werd op basis van deze scores een gemiddelde BCS berekend per dier.

Ook de veehouder scoorde de koeien één maal, met name op de eerste onderzoeksdag. De veehouder scoorde niet op dezelfde manier als de drie studenten en de dierenarts, maar gaf de dieren op het zicht een uniforme score zoals hij dat gewoon was te doen op zijn bedrijf. Hierbij gebruikte hij wel dezelfde schaal: 1 (mager) tot 5 (vet), met tussenstappen van 0,25 . Door hem werd dus geen aandacht geschonken aan het apart scoren van de acht anatomische punten. Deze manier van scoren wordt het meest gebruikt door melkveehouders, omdat deze sneller gaat dan het scoren volgens Edmonson et al. (1989).

\section{Thunder Measure-Vet Device ${ }^{\circledR}$ (Ingenera SA)}

De vierde student, opgeleid om met de TM-Vet Device te werken, stelde zich op in de voedergang en de rij vastgezette koeien werd systematisch afgelopen.

De software werd in de vorm van een applicatie geïnstalleerd op een smartphone voorzien van een camera en gekoppeld aan een apparaat met laser (Figuur 2). Een Excelbestand met de aanwezige dieren werd vooraf in de applicatie geïmporteerd, zodat tijdens het onderzoek de gewenste koe vlot uit een lijst kon geselecteerd worden.

Tijdens het scoren dient de gebruiker van het toestel zich aan de kop van het dier op te stellen. Wanneer het dier in een voederhek wordt vastgezet, kunnen de dorsale foto's genomen worden vanuit de voedergang. $\mathrm{Na}$ identificatie van het dier dient men één maal op de laserknop te drukken, waarna de laserstraal op de rug van het dier zichtbaar wordt. De overlangse laserstraal dient bij het nemen van een foto te worden gericht op de middellijn van het dier en de dwarse laserstraal moet halverwege de lendenen geplaatst worden (Figuur 3). Het toestel geeft tijdens het positioneren ook de hoek aan van de laser ten opzichte van de waterpas, zodat de foto zo nauwkeurig mogelijk horizontaal genomen wordt.

$\mathrm{Na}$ een tweede druk op dezelfde knop wordt de foto genomen, waarna die automatisch en per koe wordt opgeslagen en via een draadloze internetver- binding doorgestuurd wordt naar de server van Ingenera SA. Het is van belang om drie foto's te nemen per dier, zodat de server de foto's kan uitselecteren die niet voldoen aan bepaalde voorwaarden. Op basis van de resterende foto's wordt een gemiddeld BCS per dier berekend, waarna deze resultaten terug doorgestuurd worden naar het toestel.

\section{Backfat thickness (BFT)}

Een tweede dierenarts bepaalde met behulp van echografie de BFT van de dieren. De sonde van de echograaf (Tringa ${ }^{\circledR}$, Esaote, Nederland, 10-5 Mhz) werd ter hoogte van het laatste derde van de denkbeeldige lijn tussen de tuber coxae en tuber ischiadicum geplaatst zoals beschreven door Schröder en Staufenbiel (2006). Ook deze dierenarts positioneerde zich achter de vastgezette dieren, waardoor de benadering van de specifieke lokalisatie werd vergemakkelijkt. De gemeten waarde $(\mathrm{mm})$ werd door een helper neergeschreven op het invulformulier.

\section{Statistiek}

Alle statistische analysen werden uitgevoerd met behulp van SAS Enterprise Guide 6 (SAS Institute Inc., Cary, North Carolina, USA). De normaliteit van de data werd beoordeeld aan de hand van de kolmogorov-smirnovtest $(\mathrm{P}<0,01)$. De beschrijvende statistiek wordt weergegeven als gemiddelde \pm standaarddeviatie (SD). De Pearsons correlatiecoefficiënten werden berekend om correlaties tussen methoden en/of observaties weer te geven. Aangezien er door de veehouder maar op één moment een score werd gegeven, werd de correlatie tussen de veehouder en de studenten/dierenarts/BFT slechts bij zestig dieren berekend.

Daarnaast werd van elke methode de herhaalbaarheid berekend en werd de overeenkomst tussen de BCS en de TM-Vet Device beoordeeld.

De herhaalbaarheid van iedere methode werd bepaald aan de hand van PROC VARCOMP, volgens het volgende gemengde model: $\mathrm{Y}_{\mathrm{ijk}}=\mu+$ observatie $_{\mathrm{i}}+$ $\operatorname{dier}_{j}+\varepsilon_{\mathrm{ijk}}$ (Caroli, 1998).

waarin:

$\mathrm{Y}_{\mathrm{ijk}}$ : de te onderzoeken parameter (BCS of BFT); $\mu$ : het gemiddelde;

observatiei: "fixed effect" van de i-ste observatie;

dierj: "random effect" van het j-ste dier;

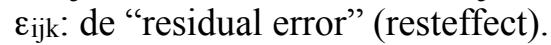

Vervolgens werd de herhaalbaarheid (R) van de methode op basis van het gemengde model berekend:

$$
R=\frac{\sigma^{2} \text { dier }_{j}}{\sigma^{2} \text { dier }_{j}+\sigma^{2} \text { error }_{i j k l}}
$$

De graad van overeenkomst tussen BCS en TMVet Device werd beoordeeld aan de hand van de bland-altmanplots en de concordantie correlatiecoëfficiënt (CCC). De benadering van Bland en Altman 
om de grenzen van overeenkomst uit te drukken, is veruit de meest populaire methode om de overeenkomst tussen twee meettoestellen of meetmethoden te onderzoeken (Hamilton en Stamey, 2007). Volgens deze benadering kan een nieuwe methode slechts aanvaard worden wanneer deze binnen een acceptabele range (de zogenaamde "limits of agreement") van een reeds gevalideerde techniek valt (Bland en Altman, 1986). De "limits of agreement" worden hierbij voorgesteld als het verschil tussen de twee metingen $\pm 1,96 \mathrm{SD}$ (95\% limits of agreement). Hoe smaller de 95\%-grens is, hoe meer de twee methoden overeenkomstig zijn (Bland en Altman, 1986).

Voor de analyse van de CCC werd de MACRO rm ccc gebruikt (Carrasco et al., 2013). Deze MĀCRO berekent Lins concordantie-correlatiecoëfficiënt (CCC) voor twee sets van resultaten. De CCC kan gebruikt worden om een nieuwe methode (of instrument) te vergelijken met de gouden standaard en werd in 1989 door Lin geïntroduceerd. De resultaten van de nieuwe methode worden geplot ten opzichte van die van de standaardmethode (Lin, 1992), wat bij perfecte overeenkomst een lijn met een hoek van $45^{\circ}$ oplevert (de concordantielijn). Vervolgens wordt de locatie (afstand en helling) van de observaties ten opzichte van de concordantielijn berekend en dit alles wordt weergegeven als een getal dat zowel de accuraatheid als de correlatie omvat. De berekende uitkomst valt binnen een schaal van -1 (perfecte nietovereenkomst, 0 (geen overeenkomst) en 1 (perfecte overeenkomst).

\section{RESULTATEN}

\section{Descriptieve resultaten}

In Tabel 1 worden het gemiddelde en de SD weer- gegeven per observatiemethode. Hierbij wordt een onderscheid gemaakt tussen de observaties van de eerste onderzoeksdag en de tweede onderzoeksdag. Daarnaast wordt het gemiddelde van beide onderzoeksdagen weergegeven.

Tijdens de twee onderzoeksdagen werden in totaal 360 foto's genomen. Van deze 360 werden in totaal tien foto's door het systeem verworpen omdat de hoek die de laserarm ten opzichte van de vloerpas makkte, te groot werd om een betrouwbare BCS weer te geven. Van de 180 foto's genomen tijdens de eerste onderzoeksdag werden er zes foto's uitgeselecteerd, terwijl er vier van de 180 foto's van de tweede onderzoeksdag uitgeselecteerd werden. Er werd nooit meer dan één foto per onderzoeksdag per dier uitgeselecteerd, waardoor er ook van de dieren met uitgeselecteerde foto's steeds twee foto's overbleven om een gemiddelde BCS te berekenen. Eens gefixeerd in het voederhek, konden de dieren vlot met de TM Vet Device gescoord worden. Per dier was ongeveer één minuut nodig voor het positioneren van de laser en het maken van drie achtereenvolgende foto's.

\section{Correlaties}

Bij elke observatie met de TM-Device werden achtereenvolgens drie foto's genomen, waaraan afzonderlijk een score werd toegekend. Het toestel geeft daarna een BCS weer die berekend is door het gemiddelde van deze drie scores te nemen. De correlaties tussen de drie opeenvolgende foto's per observatie worden in Tabel 2 weergegeven. Wanneer een foto werd uitgeselecteerd, werden slechts twee foto's weerhouden, waardoor het aantal foto's bij foto 3 slechts 110 was in plaats van 120 .

In Tabel 3 worden de correlaties tussen de resultaten van de verschillende methoden $(\mathrm{N}=120)$ weergegeven.

Tabel 1. Descriptieve resultaten.

\begin{tabular}{lccc}
\hline Methode & Observatie 1 & Observatie 2 & Gemiddeld \\
\hline TM-Vet Device & $3,1 \pm 0,44(\mathrm{n}=174)$ & $3,2 \pm 0,44(\mathrm{n}=176)$ & $3,1 \pm 0,44(\mathrm{n}=360)$ \\
BCS & & & \\
Ervaren dierenarts & $3,0 \pm 0,44(\mathrm{n}=60)$ & $3,0 \pm 0,44(\mathrm{n}=60)$ & $3,0 \pm 0,44(\mathrm{n}=120)$ \\
Student 1 & $3,6 \pm 0,35(\mathrm{n}=60)$ & $3,0 \pm 0,32(\mathrm{n}=60)$ & $3,3 \pm 0,44(\mathrm{n}=120)$ \\
Student 2 & $3,2 \pm 0,41(\mathrm{n}=60)$ & $3,2 \pm 0,39(\mathrm{n}=60)$ & $3,2 \pm 0,40(\mathrm{n}=120)$ \\
Student 3 & $3,0 \pm 0,46(\mathrm{n}=60)$ & $2,8 \pm 0,43(\mathrm{n}=60)$ & $2,9 \pm 0,46(\mathrm{n}=120)$ \\
Veehouder & $3,1 \pm 0,49(\mathrm{n}=60)$ & & $12,2 \pm 4,80(\mathrm{n}=120)$ \\
BFT (mm) & $12,3 \pm 4,75(\mathrm{n}=60)$ & $12,2 \pm 4,89(\mathrm{n}=60)$ & \\
\hline
\end{tabular}

Tabel 2. Correlatie tussen de drie verschillende foto's per dier.

\begin{tabular}{lll}
\hline & Foto $2(\mathbf{N}=120)$ & Foto $3(\mathbf{N}=\mathbf{1 1 0})$ \\
\hline Foto 1 $(\mathrm{N}=120)$ & $0,96^{* * *}$ & $0,96^{* * *}$ \\
Foto 2 $(\mathrm{N}=120)$ & & $0,97^{* * *}$ \\
\hline
\end{tabular}

$* * * \mathrm{P}<0.001$ 


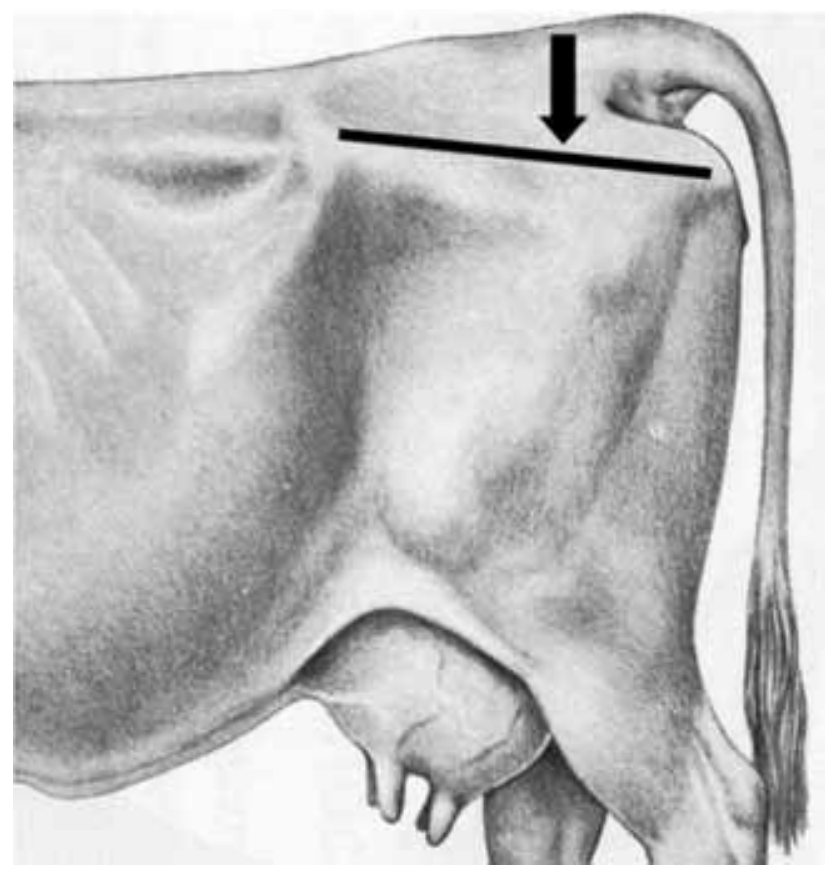

Figuur 1. Lokalisatie van de sonde bij de BFT-bepaling. (Bron: Schröder en Staufenbiel, 2006).

Uit de tabel kan afgeleid worden dat de TM-Device een lage correlatie $(\mathrm{r}=0,38 ; \mathrm{P}<0,001)$ heeft met de BFT. De correlatie van de TM-Device met de gemiddelde BCS gescoord door de ervaren dierenarts is daarentegen $0,82(\mathrm{P}<0,001)$. De correlatie tussen de TM-Device en de gemiddelde BCS gescoord door de onervaren studenten varieert van 0,45 tot 0,74 $(\mathrm{P}<0,001)$. De correlatie tussen de gemiddelde BCS gescoord door de ervaren dierenarts en de studenten varieert tussen 0,56 en $0,87(\mathrm{P}<0,001)$.

De correlatie tussen de BFT en de BCS gescoord door de ervaren dierenarts is $0,64(\mathrm{P}<0,001)$. Wanneer de tabel van Edmonson et al. (1989) nader bekeken wordt, ziet men specifiek bij het zesde punt "between pins and hooks" dat exact dezelfde regio beoordeeld

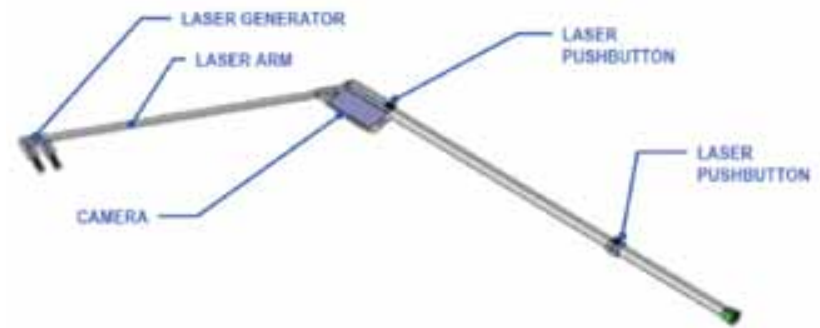

Figuur 2. TM-Vet Device (Bron: Ingenera SA, Zwitserland).

wordt als deze gebruikt voor de echografische rugvetdiktemeting. Daarom werd de correlatie tussen de echografische vetdiktemeting en de visuele score van deze specifieke anatomische lokalisatie apart berekend (Tabel 4).

\section{Herhaalbaarheid van de verschillende methoden}

Voor elke methode/observator werden de observaties van beide onderzoeksdagen tegen elkaar uitgezet om de herhaalbaarheid van de metingen weer te geven. Daarnaast werd het verschil tussen de observaties berekend en uitgezet ten opzichte van het gemiddelde van beide observaties (bland-altmanplot). Het gemiddelde verschil wordt weergegeven als gemiddelde \pm SD (Tabel 5).

\section{Overeenkomst tussen de verschillende meetmetho- den}

\section{"Enhanced bland-altmanplot"}

In de "enhanced bland-altmanplot" werd voor iedere meting het verschil in conditiescore (TM-Vet Device - BCS ervaren dierenarts) of de bias (y-as)

Tabel 3. Correlaties tussen de verschillende methoden.

\begin{tabular}{|c|c|c|c|c|c|c|}
\hline & TM-Vet Device & $\begin{array}{l}\text { Ervaren } \\
\text { dierenarts }\end{array}$ & Student 1 & Student 2 & Student 3 & Veehouder \\
\hline BFT & $0,38 * * *$ & $0,64 * * *$ & $0,30 * *$ & $0,55^{* * *}$ & $0,49 * * *$ & $0,71 * * *$ \\
\hline TM-Vet Device & & $0,82 * * *$ & $0,45 * * *$ & $0,74 * * *$ & $0,66^{* * *}$ & $0,60 * * *$ \\
\hline Ervaren dierenarts & & & $0,56 * * *$ & $0,87 * * *$ & $0,83 * * *$ & $0,80 * * *$ \\
\hline Student 1 & & & & $0,58 * * *$ & $0,72 * * *$ & $0,57 * * *$ \\
\hline Student 2 & & & & & $0,81 * * *$ & $0,81 * * *$ \\
\hline Student 3 & & & & & & $0,71 * * *$ \\
\hline
\end{tabular}

$* * \mathrm{P}<0.01 \quad * * * \mathrm{P}<0.001$

Tabel 4. Correlatie tussen BFT en "between pins and hooks".

\begin{tabular}{lcccc}
\hline & Dierenarts & Student 1 & Student 2 & Student 3 \\
\hline Vetdiktemeting & $0,51 * * *$ & 0,02 & $0,44 * * *$ & $0,30 * * *$ \\
\hline
\end{tabular}




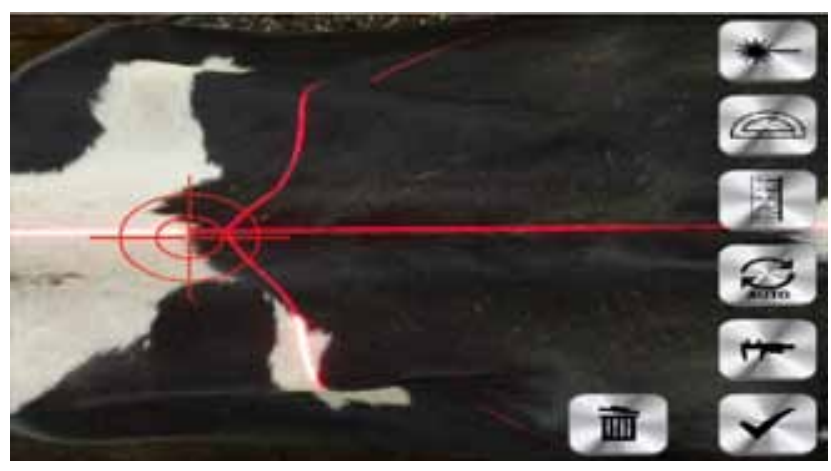

Figuur 3. Positie van de laserstraal (Bron: Ingenera SA, Zwitserland).

geplot ten opzichte van de standaard meting in de $\mathrm{X}$-as (de BCS gescoord door de ervaren dierenarts) (Figuur 4). De nul-biaslijn snijdt de 95\% betrouwbaarheidsband. Dit toont aan dat er een significante regressie (in dalende lijn) aanwezig is, waardoor een heterogene bias vastgesteld kan worden.

\section{Concordantie-correlatiecoëfficiënt (CCC)}

De schatting van de CCC toont een hoge graad van overeenkomst aan $(0,831 ; 95 \%$ CI: $0,732-0,895)$ tussen de BCS bepaald door de ervaren dierenarts en bepaald door de TM-Vet Device. Er kan een systematisch verschil tussen de BCS-bepaling van de ervaren dierenarts en de BCS-bepaling via TM-Vet Device gezien worden. De grootste reden van het verschil is, zoals blijkt uit de bland-altmananalyse, de koe zelf $(0,158)$ en de combinatie koe-methode $(0,019)$, terwijl het systematisch verschil tussen de methoden slechts op 0,017 geschat wordt.

\section{DISCUSSIE}

In het hier beschreven onderzoek werd nagegaan in hoeverre de TM-Vet Device kan ingezet worden om op een geautomatiseerde, objectieve en herhaalbare manier de hoeveelheid subcutaan opgeslagen vet bij melkkoeien te schatten. Hiervoor werd het toestel

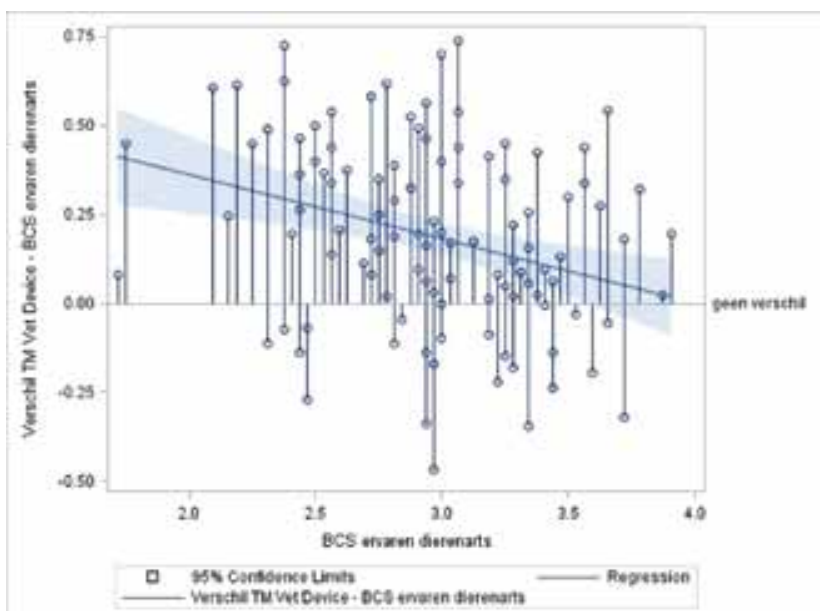

Figuur 4. Enhanced bland-altmanplot: het verschil in conditiescore (TM-Vet Device - BCS ervaren dierenarts) wordt geplot ten opzichte van de standaard meting (BCS ervaren dierenarts).

door een onervaren persoon gebruikt om kort na elkaar zestig dieren (zowel hoogdrachtige pinken als koeien op verschillende momenten in de lactatiecyclus) met een variabele conditie te scoren. Daartoe werden de resultaten bekomen met het toestel, vergeleken met de resultaten bekomen via visuele conditiescorebepaling door een ervaren dierenarts en enkele onervaren studenten diergeneeskunde. Bovendien werd deze nieuwe methodiek vergeleken met de echografisch gemeten BFT.

Uit de resultaten blijkt dat dit innovatief hulpmiddel om de hoeveelheid opgeslagen subcutaan vet bij melkkoeien te meten, snel en eenvoudig is in gebruik, op voorwaarde dat de dieren goed gefixeerd kunnen worden. Van de 360 foto's die genomen werden met het apparaat, werden er slechts tien uitgeselecteerd omwille van een foute positionering. Bovendien werd aangetoond dat het weglaten van één foto de resultaten slechts heel beperkt beïnvloedt. De gelukte foto's worden gebruikt om op basis van de contouren van het dier, zoals weergegeven op de foto, de conditie van de dieren te schatten. Hiertoe worden de foto's vergeleken met de standaarden die zich in de data-

Tabel 5. Herhaalbaarheid van de verschillende methoden/observatoren.

\begin{tabular}{lccc}
\hline Methode & $\begin{array}{c}\text { Verschil tussen } \\
\text { 2 observaties }(\mathbf{g e m} \pm \mathbf{S D})\end{array}$ & $\begin{array}{c}\text { Observaties binnen } \\
\text { interval gem } \pm \mathbf{1 , 9 6 S D}\end{array}$ & $\begin{array}{c}\text { Herhaalbaarheid } \\
\mathbf{( \% )}\end{array}$ \\
\hline TM-Vet Device & $0,0 \pm 0,19$ & 91,7 & 91 \\
BCS & & & \\
Ervaren dierenarts & $0,0 \pm 0,14$ & 95 & 93 \\
Student 1 & $-0,61 \pm 0,31$ & 96,7 & 66 \\
Student 2 & $0,0 \pm 0,25$ & 95 & 80 \\
Student 3 & $-0,2 \pm 0,27$ & 95 & 81 \\
BFT (mm) & $0,1 \pm 1,28$ & 93,3 & 96 \\
\hline
\end{tabular}


bank van de software bevinden. De algoritmen die hiervoor worden gebruikt, werden door het bedrijf echter niet vrijgegeven. Het is algemeen bekend dat het schatten van de BCS op basis van beeldanalyse soms bemoeilijkt wordt door het typische kleurpatroon in de aftekeningen van het dier (Bewley et al., 2008; Leroy, 2005).

De BCS bepaald met behulp van de TM-Vet Device vertoont een sterke overeenkomst met die bepaald door een ervaren dierenarts, zelfs wanneer een onervaren persoon het apparaat hanteert. Daarnaast hebben beide methoden ook een vergelijkbare en hoge herhaalbaarheid. Conditiescores op basis van de visuele methode en uitgevoerd door studenten die hiermee geen enkele ervaring hadden, bleken echter een veel lagere correlatie met de gouden standaard te hebben en bleken bovendien een beduidend lagere herhaalbaarheid te hebben. Dit laatste bevestigt de kritiek die eerder door Kristensen et al. (2006) en door Bewley et al. (2008) werd aangehaald als een belangrijke reden om op zoek te gaan naar meer geautomatiseerde methoden die tevens een hogere betrouwbaarheid en herhaalbaarheid hebben. Uit de bekomen resultaten van de voorliggende studie kan bovendien geconcludeerd worden dat personen die helemaal geen ervaring hebben met het scoren van de lichaamsconditie bij melkkoeien, dit blijkbaar op een betrouwbaardere manier kunnen doen aan de hand van de TM-Vet Device dan aan de hand van de visuele methode zoals voorgesteld door Edmonson et al. (1989) die hen op korte termijn wordt aangeleerd. De hogere overeenkomst tussen de veehouder en de ervaren dierenarts zet deze stelling kracht bij. Ervaring is blijkbaar van doorslaggevend belang voor het herhaalbaar uitvoeren van een BCS.

Uit de bekomen resultaten blijkt wel dat er een zekere afwijking wordt waargenomen wanneer de BCSbepaling van de TM-Vet Device vergeleken wordt met die van een ervaren dierenarts. Bij magerdere dieren wordt een overschatting van de BCS waargenomen, maar deze neemt af naarmate de conditie toeneemt. Bij vettere dieren (met een hogere BCS gegeven door de ervaren dierenarts), wordt dus door het apparaat wel een BCS weergegeven die deze van de dierenarts benadert. Aangezien vooral dieren met een hogere BCS $(>3,5)$ kans hebben op latere gezondheidsproblemen (Morrow, 1976; De Koster en Opsomer, 2012), zijn dit de dieren waarbij de bepaling van de conditie het belangrijkste is. Er kan dus gesteld worden dat de applicatie een betrouwbare tool is om risicodieren op te sporen. Doordat er in het hier beschreven onderzoek geen dieren waren met een BCS van 4 of hoger, kan er echter geen uitspraak worden gedaan over het scoren van dergelijk vervette dieren.

De BFT was één van de eerste pogingen om de methodiek ter bepaling van de hoeveelheid opgeslagen subcutaan vet te objectiveren. Via deze methode trachtte men door het echografisch meten van de hoeveelheid subcutaan vet opgeslagen ter hoogte van het bekkengebied, een beeld te krijgen van de totale hoeveelheid vet opgeslagen in het lichaam van de koe. Het onderzoek werd op punt gezet door Staufenbiel (1993) die eerder door middel van een punctiemethode had aangetoond dat de hoeveelheid vet die op die specifieke plaats is opgeslagen, een goede weergave is van de totale hoeveelheid opgeslagen vet (Staufenbiel, 1993). Bij de BFT wordt gebruik gemaakt van een B-mode echografietoestel met een lineaire sonde van 5 tot 7,5 MHz. Er wordt gemeten op het caudale einde (ongeveer ter hoogte van het caudale vierde) op de lijn die de tuber ischiadicum verbindt met de tuber coxae. Wanneer daar de sonde van het echografietoestel wordt geplaatst, kan de fascia profunda boven de gluteusmusculatuur duidelijk worden waargenomen. Van de ruimte die tussen deze fascia profunda en de opperste dorsale zijde van het in beeld gebrachte weefsel gemeten wordt, wordt $5 \mathrm{~mm}$ afgetrokken om de dikte van de huid in rekening te brengen, terwijl de rest als vetopslag wordt aanzien (Schröder en Staufenbiel, 2006). Alhoewel er een aantal zaken zijn die men in vraag kan stellen qua accuraatheid van deze meetmethode (zwakke standaardisatie van de plaats waar precies gemeten moet worden, de dikte van de huid, de druk die men uitoefent bij het meten), kwam zowel in eerder als in het hier beschreven onderzoek naar voor dat deze methode een hoge herhaalbaarheid heeft.

Er dient opgemerkt te worden dat de bepaling van de BCS zich beperkt tot het inschatten van de hoeveelheid subcutaan opgeslagen vet. Eerder werd door de auteurs van de huidige studie aangetoond dat de hoeveelheid subcutaan opgeslagen vet niet altijd gecorreleerd is aan de hoeveelheid vet opgeslagen in het abdomen (Van Eetvelde et al., 2011). Met andere woorden, koeien die een normale BCS hebben, kunnen wel degelijk een te grote hoeveelheid vet hebben opgeslagen in het abdomen. Aangezien bekend is dat 'abdominaal vervetten' nog gevaarlijker is dan 'subcutaan vervetten' (De Koster en Opsomer, 2012), is er momenteel ook onderzoek aan de gang waarbij men op een accurate manier de hoeveelheid abdominaal opgeslagen vet tracht te bepalen (Desmet, 2013).

Wanneer er in het managementprogramma van een hoogproductieve melkveestapel gekozen moet worden tussen het aanleren van de BCS-bepaling volgens Edmonson et al. (1989) of het gebruik van de TM-Vet Device, kan geconcludeerd worden dat het gebruik van het toestel de voorkeur verdient door de hogere betrouwbaarheid, inclusief herhaalbaarheid, van de bekomen resultaten. Ook de eenvoud in gebruik en de benadering van de dieren vanuit de voedergang zorgen ervoor dat het toestel zijn plaats zou kunnen krijgen in het managen van een melkveestapel. Wanneer het in deze studie uitgeteste toestel zou kunnen bevestigd worden op een vast systeem zoals bijvoorbeeld in een melkrobot, zou dit mogelijkheden bieden om de BCS automatisch en op zeer regelmatige tijdstippen uit te voeren, wat zeker een meerwaarde zou betekenen bij het nutritioneel managen van een modern melkveebedrijf. 


\section{REFERENTIES}

Bewley J. M., Peacock A., Lewis O., Boyce R., Roberts D., Coffey M., Schutz M. (2008). Potential for estimation of body condition scores in dairy cattle from digital images. Journal of Dairy Science 91, 3439-3453.

Bercovich A., Edan Y., Alchanatis V., Moallem U., Parmet Y., Honig H., Maltz E., Antler A., Halachmi I. (2013). Development of an automatic cow body condition scoring using body shape signature and Fourier descriptors. Journal of Dairy Science 96, 8047-8059.

Bines A. J., Hart I. C. (1982). Metabolic limits to milk production especially roles of growth hormone and insulin. Journal of Dairy Science 65, 1375-1389.

Bland J.M., Altman D.G. (1986). Statistical methods for assessing agreement between two methods of clinical measurement. Lancet 1, 307-310.

Bossaert P. (2010). The role of insulin in the energy conflict between milk production and ovarian activity during the transition period of high-yielding dairy cows. Doctoraatthesis Faculteit Diergeneeskunde Gent, 1-258.

Brethour J. R. (1992). The repeatability and accuracy of ultrasound in measuring backfat of cattle. Journal Animal Science 70, 1039-1044.

Caroli A. (1998). Use of the sas varcomp procedure to estimate analytical repeatability. In: SAS European Users Group International Proceedings/SEUGI 1998.

Carrasco J.L., Phillips B.R., Puig-Martineza J., King T.S., Chinchilli V.M. (2013). Estimation of the concordance correlation coefficient for repeated measures using SAS and R. Computer Methods and Programs in Biomedicine 109, 293-304.

De Koster J., Opsomer G. (2012). Are modern dairy cows suffering from modern diseases? Vlaams Diergeneeskundig Tijdschrift 81, 71-80.

De Koster J., Opsomer G. (2013). Insulin resistance in dairy cows. Veterinary Clinics of North America: Food Animal Practice 29, 299-322.

Desmet K. (2013). Schatting van de hoeveelheid lichaamsvet bij melkvee met behulp van bio-elektrische impedantie analyse. Onderzoek in het kader van de Masterproef, Faculteit Diergeneeskunde (UGent), pp 55.

Domecq J. J. (1995). Validation of body condition scores with ultrasound measurements of subcutaneous fat of dairy cows. Journal of Dairy Science 78, 2308-2313.

Edmonson A., Lean I., Weaver L., Farver T., Webster G. (1989). A body condition scoring chart for Holstein dairy cows. Journal of Dairy Science, 72, 68-78.

Halachmi I., Klopcic M., Polak P., Roberts D.J., Bewley J.M. (2013). Automatic assessment of dairy cattle body condition score using thermal imaging. Computers and Electronics in Agriculture 99, 35-40.

Halachmi I., Polak P., Roberts D. J., Klopcic M. (2008). Cow body shape and automation of condition scoring. Journal of Dairy Sciences 91, 4444-4451.
Hamilton C., Stamey J. (2007). Using Bland-Altman to asses agreement between two medical devices. Journal of Clinical Monitoring and Computing 21, 331-333.

Klawuhn D., Staufenbiel R. (1997). Aussagekraft der Rückenfettdicke zum Körperfettgehalt beim Rind. Tierärtzliche Praxis 25, 133-138.

Kristensen E., Dueholm L., Vink D., Andersen J.E., Jakobsen E.B., Illum-Nielsen S., Petersen F.A., Enevoldsen C. (2006). Within and across person uniformity of body condition scoring in Danish Holstein cattle. Journal of Dairy Science 89, 3721-3728.

Leroy T. J. (2005). Automatic determination of body condition score of cows based on 2D images. In: Precision Livestock Farming. (Wageningen Academic Publishers), 251-255.

Lin L. (1989). A concordance correlation coefficient to evaluate reproducibility. Biometrics 45, 255-268.

Lin L. (1992). Assay validation using the concordance correlation coefficient. Biometrics 48, 599-604.

Morrow D.A. (1976). Fat cow syndrome. Journal of Dairy Science 59, 1625-1629.

Pryce J.E., Wales W.J., de Haas Y., Veerkamp R.F., Hayes B.J. (2014). Genomic selection for feed efficiency in dairy cattle. Animal 8, 1-10.

Roche J.R., Dillon P.G., Stockdale C.R., Baumgard L.H., VanBalle M.J. (2004). Relationships among international body condition scoring systems. Journal of Dairy Science 87, 3076-3079.

Roche J.R., Friggens N.C., Kay J.K., Fisher M.W., Stafford K.J., Berry D.P. (2009). Body condition score and its association with dairy cow productivity, health, and welfare. Journal of Dairy Science 92, 5769-5801.

Roche J.R., Kay J.K., Friggens N.C., Loor J., Berry D.P. (2013). Assessing and managing body condition score for the prevention of metabolic disease in dairy cows. Veterinary Clinics of North America: Food Animal Practice 29, 323-336.

Schröder U., Staufenbiel R. (2006). Invited review: methods to determine body fat reserves in the dairy cow with special regard to ultrasonographic measurement of backfat thickness. Journal of Dairy Science 89, 1-14.

Staufenbiel R. (1993). Energie- und Fettstoffwechsel des Rindes unter besonderer Berücksichtigung der Messung der Rückenfettdicke und der Untersuchung von Fettgewebe. Habilitationsschrift Freie Universität Berlin, pp. 468.

Tamminga S., Luteijn P.A., Meijer R.G.M. (1997). Changes in composition and energy content of liveweight loss in dairy cows with time after parturition. Livestock Production Science 52, 31-38.

Van Eetvelde M., De Smet S., Opsomer G. (2011). Het inschatten van energiereserves onder de vorm van vet bij hoogproductieve melkkoeien. Vlaams Diergeneeskundig Tijdschrift 80, 31-37. 